\title{
Feasibility of a procedure does not always translate to what is most efficacious
}

\author{
Michael Lanuti, MD
}

\author{
From the Division of Thoracic Surgery, Massachusetts General Hospital and Harvard Medical School, Boston, \\ Mass. \\ Disclosures: Author has nothing to disclose with regard to commercial support. \\ Received for publication Feb 29, 2016; accepted for publication March 1, 2016; available ahead of print March 23 , \\ 2016. \\ Address for reprints: Michael Lanuti, MD, 55 Fruit St, Blake 1570, Boston, MA 02114 (E-mail: mlanuti@ \\ partners.org). \\ J Thorac Cardiovasc Surg 2016;151:e109 \\ $0022-5223 / \$ 36.00$ \\ Copyright (c) 2016 by The American Association for Thoracic Surgery \\ http://dx.doi.org/10.1016/j.jtcvs.2016.03.004
}

Primary neoplasms of the trachea are infrequent, and curative therapy often involves segmental tracheal resection and reconstruction \pm adjuvant radiation with some limitations. Tumor length greater than 3 to $5 \mathrm{~cm}$ and radial extension of tumor into surrounding mediastinal structures may preclude safe resection and reconstruction. The majority of primary tracheal tumors are squamous cell carcinoma or adenoid cystic carcinoma (ACC). ACCs, previously named "cylindroma," can harbor an aggressive nature whereby the mucosal extent of tumor can grossly underestimate the mural or extramural spread. In a report of 108 consecutive patients who underwent open tracheal resection and reconstruction for ACC, airway and radial resection margins were important prognostic factors for overall and disease-free survival. ${ }^{1}$ Microscopically positive airway margins were associated with lower survival and correlated with worse disease-free survival. Published reports on outcomes of resected tracheal tumors are limited to single institution series in which only open transcervical or transthoracic operative techniques were used.

In this case report of the Journal, Shao and colleagues ${ }^{2}$ describe a novel technique of tracheal resection and reconstruction via mediastinoscopy under conscious sedation for a midtracheal ACC. The authors acknowledge the use of spontaneous breathing anesthesia on more than 1200 video-assisted thoracoscopic surgery cases and implemented this anesthetic technique for tracheal resection of a malignant airway tumor. Of note, awake upper airway surgery has been reported by Macchiarini and colleagues ${ }^{3}$ in 20 consecutive patients with nonmalignant tracheal stenosis. Permissive hypercapnia was well tolerated in those patients with no complications. In this young patient, the obstructing tumor was debulked bronchoscopically 1 month before definitive resection. In preparation for tracheal resection, the authors performed bronchoscopic mucosal biopsies $1 \mathrm{~cm}$ around the original bed of the tumor to assess the presence of invasive disease and plan their operation. One must proceed with great caution when trying to assess the extent of ACC using bronchoscopic visualization and

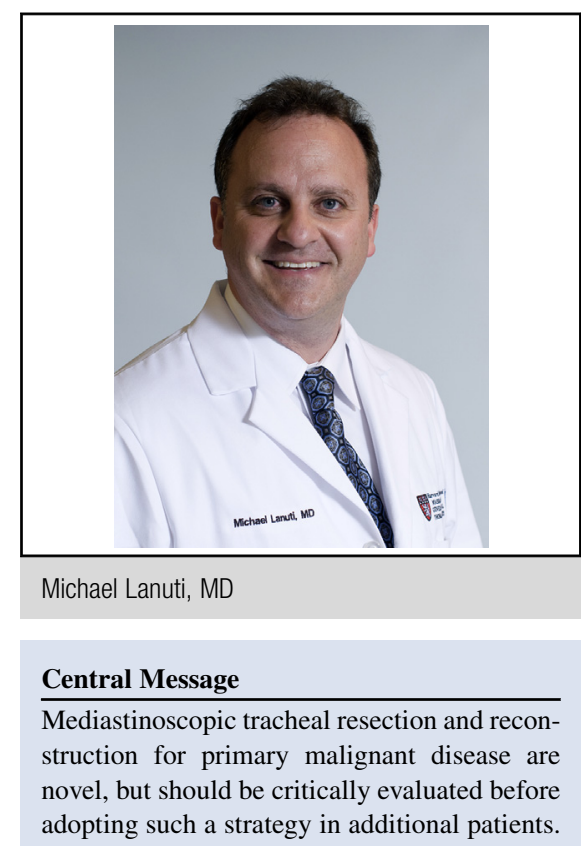

See Article page e105.

biopsy. Because the best chance of cure in this patient population is surgery, any compromise to the oncologic conduct of the operation can subject the patient to a lifetime of recurrence or radiation-related sequelae. Although the authors successfully completed the operation with a mediastinoscope and achieved negative frozen-section margins, I would not advocate for this technique for primary malignant disease of the trachea even if the segmental resection is small. The authors speculate that this minimally invasive approach reduces surgical injury compared with the traditional open approach. One could postulate that the risk of recurrent laryngeal nerve injury or anastomotic separation may increase given the limited field of view with this technique. Most important, long-term follow-up of this patient would be paramount before routinely adopting this strategy in selected patients with primary tracheal neoplasms.

\section{References}

1. Honings J, Gaissert HA, Weinberg AC, Mark EJ, Wright CD, Wain JC, et al. Prognostic value of pathologic characteristics and resection margins in tracheal adenoid cystic carcinoma. Eur J Cardiothorac Surg. 2010;37:1438-44.

2. Shao W, Shen J, Ying W, He J. Mediastinoscopic tracheal resection and reconstruction under spontaneous breathing anesthesia. J Thorac Cardiovasc Surg. 2016;151:e105-7.

3. Macchiarini P, Rovira I, Ferrarello S. Awake upper airway surgery. Ann Thorac Surg. 2010;89:387-91 